\title{
Vertical Transmission of Mycoplasma pneumoniae Infection
}

\author{
Benedikt M. Huber ${ }^{a}$ Patrick M. Meyer Sauteur ${ }^{b}$ Wendy W.J. Unger ${ }^{c}$ Paul Hasters ${ }^{a}$ \\ Marcel R. Eugster ${ }^{d}$ Simone Brandt ${ }^{e}$ Guido V. Bloemberg ${ }^{f} \quad$ Giancarlo Natalucci $^{a}$ \\ Christoph Berger ${ }^{b, f}$
}

${ }^{a}$ Department of Neonatology, University Hospital Zurich, Zurich, Switzerland; ${ }^{b}$ Division of Infectious Diseases and Hospital Epidemiology, and Children's Research Center (CRC), University Children's Hospital Zurich, Zurich, Switzerland; 'Laboratory of Pediatrics, Division of Pediatric Infectious Diseases and Immunology, Erasmus MC University Medical Center Sophia Children's Hospital, Rotterdam, The Netherlands; ${ }^{d}$ Unilabs Duebendorf, Molecular Diagnostics, Duebendorf, Switzerland; e Institute of Pathology and Molecular Pathology, University Hospital Zurich, Zurich, Switzerland; ${ }^{\mathrm{f}}$ Institute of Medical Microbiology, University of Zurich, Zurich, Switzerland

\section{Established Facts}

- Mycoplasma pneumoniae causes pneumonia predominantly in school-aged children and young adults.

- Neonatal pneumonia associated with M. pneumoniae has been very rarely reported.

\section{Novel Insights}

- Vertical transmission of Mycoplasma pneumoniae infection was demonstrated in this case, the first time with the detection of M. pneumoniae by PCR and immunohistochemistry in placental tissue.

- M. pneumoniae can be considered as possible cause of congenital pneumonia in addition to other mycoplasmas (M. hominis) and ureaplasmas (U. urealyticum and U. parvum).

\section{Keywords}

Congenital infection - Mycoplasma pneumoniae · Neonatal pneumonia $\cdot$ Vertical transmission

\begin{abstract}
Mycoplasma pneumoniae is a significant cause of pneumonia in school-aged children and young adults. We report a case of neonatal M. pneumoniae pneumonia in a preterm child manifesting in the first hours of life. Vertical transmission was demonstrated by the detection of $M$. pneumoniae in inflamed placental tissue indicating chorioamnionitis.
\end{abstract}

C 2018 S. Karger AG, Basel

\section{KARGER}

(c) 2018 S. Karger AG, Basel

E-Mail karger@karger.com

www.karger.com/neo

\section{Introduction}

Mycoplasma pneumoniae colonizes the upper respiratory tract [1] and causes pneumonia predominantly in school-aged children and young adults [2]. In contrast, other mycoplasmas and ureaplasmas colonize the urogenital tract, among which $M$. hominis, U. urealyticum, and $U$. parvum may cause ascending intrauterine infection that can lead to adverse pregnancy outcomes and/or

B.M.H. and P.M.M.S. contributed equally to this work. 
neonatal pneumonia $[3,4]$. Here, we present a preterm infant with severe neonatal $M$. pneumoniae pneumonia acquired by vertical infection.

\section{Case Report}

A preterm male neonate weighing $1,500 \mathrm{~g}$ was delivered by a 30 -year-old woman at 29 4/7 weeks of gestation by cesarean section because of recurrent vaginal bleedings and premature contractions for 3 days. Antenatal steroid administration had been completed. The Apgar score was 2, 4, and 9 at 1, 5, and $10 \mathrm{~min}$, respectively, and the umbilical artery $\mathrm{pH}$ was 7.31. He developed a severe respiratory distress syndrome (RDS) in the first hour of life requiring mechanical ventilation and surfactant administration. Chest X-ray showed a granular appearance of both lungs with air bronchograms (Fig. 1a). Empiric antibiotic treatment with amoxicillin and gentamicin was immediately started. After $24 \mathrm{~h}$, extubation was achieved and followed by nasal continuous positive airway pressure treatment. Antibiotic treatment was discontinued based on negative blood cultures and C-reactive protein within the normal range. Secondary respiratory distress developed on the second day of life (DOL) and necessitated re-intubation until DOL 4 and again from DOL 6 to 11. Chest X-ray on DOL 6 revealed multifocal opacifications and consolidations (Fig. 1b). Because of the atypical RDS presentation, an extensive diagnostic workup was performed: cultures from blood and tracheal aspirate were repeatedly negative for bacteria, as well as for fungi, as were cultures from urine for cytomegalovirus. There were no signs and symptoms of multiorgan involvement. Blood cell count showed a leukocytosis of $41 \times 10^{9} / \mathrm{L}$ after birth, which increased to a maximum of $97 \times 10^{9} / \mathrm{L}$ on DOL 2 and consisted of mainly neutrophils, including immature granulocytes. There was no evidence of leukemia or transient myeloproliferative disorder. C-reactive protein remained normal over the course of disease.

The unclear situation led to a detailed review of the medical history during pregnancy: the mother recalled a mild respiratory tract infection with intractable cough at 20 gestational weeks lasting for a week, but this was left untreated. The diagnostic workup in the neonatal tracheal aspirate was extended by M. pneumoniaespecific PCR as previously described [5]: M. pneumoniae DNA could be detected in tracheal aspirate on DOL 3 and in a second sample from nasopharyngeal aspirate after extubation on DOL 4. No DNA of M. hominis, M. genitalium, or Ureaplasma spp. was found in the tracheal aspirate by PCR, performed as described previously $[6,7]$. Treatment with erythromycin was initiated orally on DOL 4 (50 mg/kg/dose 4 times a day) and switched to intravenous application from DOL 7 to DOL 18 (40 mg/kg/dose 4 times a day). Erythromycin treatment was paralleled by a steady and sustainable improvement of clinical and radiographic findings. Chest X-ray on DOL 9 returned almost to normal. On DOL 22, the white blood cell count was normal and serological testing using an enzymelinked immunosorbent assay (Serion $\mathrm{GmbH}$, Würzburg, Germany) revealed $M$. pneumoniae-specific immunoglobulin (Ig) $\mathrm{M}$ and IgG antibodies of $<5 \mathrm{U} / \mathrm{mL}$ (cutoff $17 \mathrm{U} / \mathrm{mL}$ ) and $65 \mathrm{U} / \mathrm{mL}$ (cutoff $15 \mathrm{U} / \mathrm{mL}$ ), respectively. Nasal continuous positive airway pressure treatment was followed until DOL 23 and supplemental oxygen administered until DOL 30, defining mild bronchopulmonary dysplasia. The infant was discharged with 8 weeks of age at $376 / 7$ weeks postmenstrual age. A 1-month follow-up was uneventful.

Congenital Mycoplasma pneumoniae

Infection
Maternal serum obtained 2 weeks after birth was tested positive for M. pneumoniae-specific IgM (93 U/mL; cutoff $17 \mathrm{U} / \mathrm{mL})$ and IgG (>200 U/mL; cutoff $30 \mathrm{U} / \mathrm{mL})$, indicating a recent infection. Prepartal maternal swabs from the cervix uteri were negative by PCR for DNA of Chlamydia trachomatis and Neisseria gonorrhoe$a e$, and also vaginal swab cultures were negative. Histological examination of the placenta showed distinct chorioamnionitis and vasculitis with infiltration of neutrophils into the chorioamniotic mesoderm layer and amnion (Fig. 1c, e). Placental tissues embedded in paraffin were tested positive for M. pneumoniae DNA by PCR and $M$. pneumoniae antigens by immunohistochemistry (Fig. 1d, f). Placental tissue was tested negative for DNA of Ureaplasma spp., M. hominis, and M. genitalium by PCR. Control placental tissues without chorioamnionitis and chorioamnionitis of other origin were tested negative for M. pneumoniae antigens by immunohistochemistry (data not shown).

\section{Discussion}

Congenital pneumonia arises from direct mucosal seeding from infected amniotic fluid (chorioamnionitis), which is caused by hematogenous transplacental infection or ascending infection across the chorioamniotic membranes [8]. Maternal vaginal colonization is a key risk factor for an ascending intrauterine infection and/or perinatal infection during passage through the birth canal [8]. Mycoplasmas are primarily mucosal pathogens, among which genital mycoplasmas and ureaplasmas colonize the urogenital tract. M. hominis, U. urealyticum, and $U$.parvum are also associated with neonatal pneumonia $[3,4]$. In contrast, $M$. pneumoniae is known to exclusively colonize the respiratory tract [3]. The question arises whether chorioamnionitis in our case was caused by a so far not reported ascending infection or rather by spread from respiratory tract infection through the bloodstream to the placenta. In line with the latter, M. pneumoniae has been reported to disseminate in the bloodstream during or after a respiratory tract infection and to cause extrapulmonary manifestations [9-12]. The mother indeed experienced a cough around 8 weeks before birth and the serology after birth confirmed a recent $M$. pneumoniae infection. This respiratory infection may haveled to invasive infection and spread of M. pneumoniae to the placenta. In fact, infections with M. hominis, $U$. urealyticum, or $U$. parvum as potential cause of adverse pregnancy outcome and/or neonatal pneumonia were excluded. Thus, the diagnosis of vertical $M$. pneumoniae infection in our case is established as follows: (1) maternal respiratory tract infection at 20 gestational weeks with strongly positive $M$. pneumoniae serology 2 weeks after birth; (2) detection of M. pneumoniae in placental tissue by PCR and immuno- 

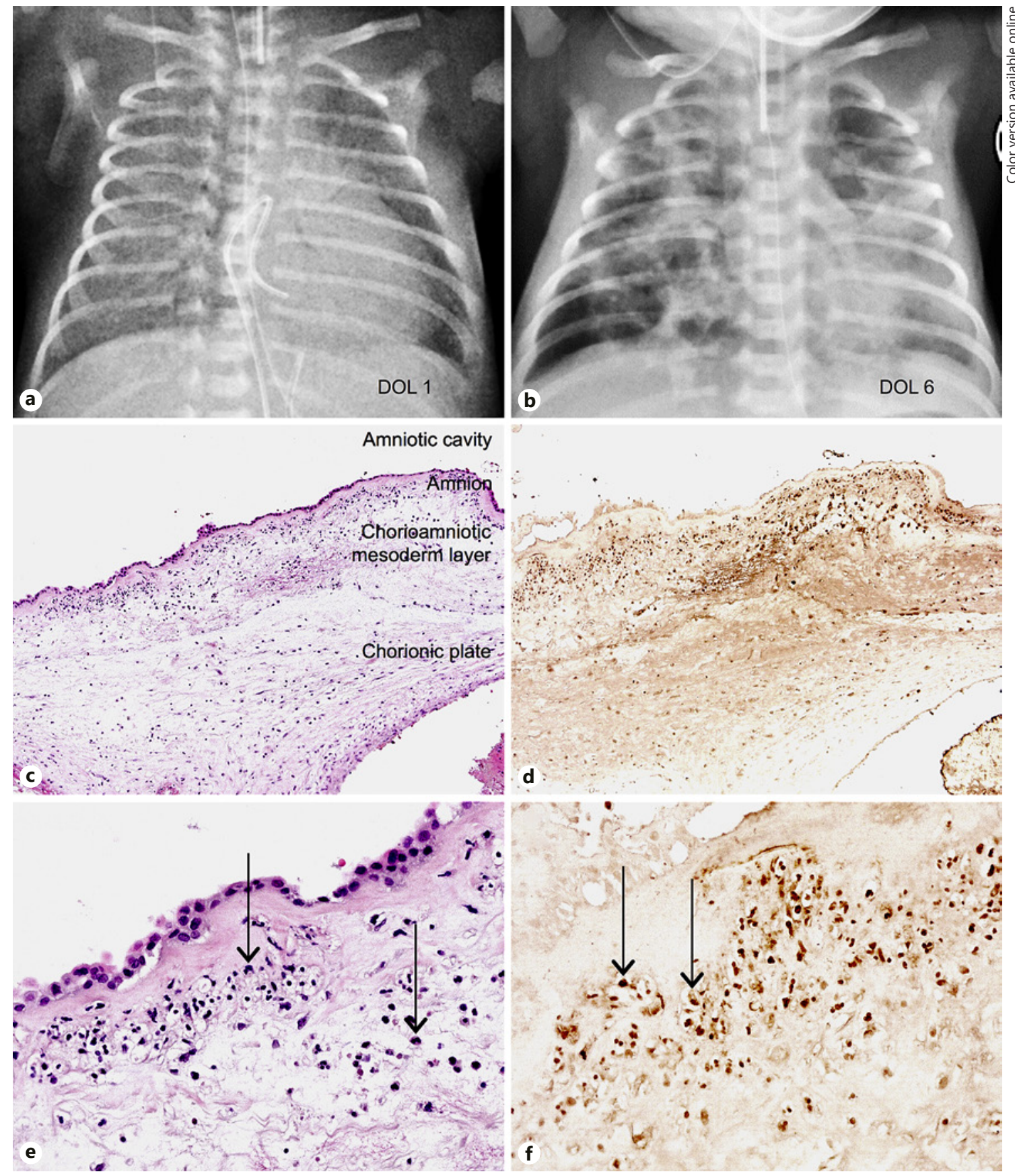

Fig. 1. a Chest X-ray, on day of life (DOL) 1, showing a diffuse interstitial pattern with granular appearance and air bronchograms of both lungs. b Chest X-ray, on DOL 6, showing reticular (bullous) multifocal opacifications and consolidations. c, e Chorioamnionitis with infiltration of neutrophils (arrows) into the chorioamniotic mesoderm layer and amnion. Hematoxylin and eosin stain. Original magnification $\times 100(\mathbf{c})$ and $\times 400(\mathbf{e})$. d, f Immunohistochemical analysis of placental tissue performed by using a biotinylated polyclonal anti-M. pneumoniae antibody (Thermo Scientific, Waltham, MA, USA) and an avidin-biotin-peroxidase complex with 3,3-diaminobenzidine tetrahydrochloride chromogenic substrate showing positive staining in the chorioamniotic mesoderm layer and amnion. Original magnification $\times 100(\mathbf{d})$ and $\times 400(\mathbf{f})$. 


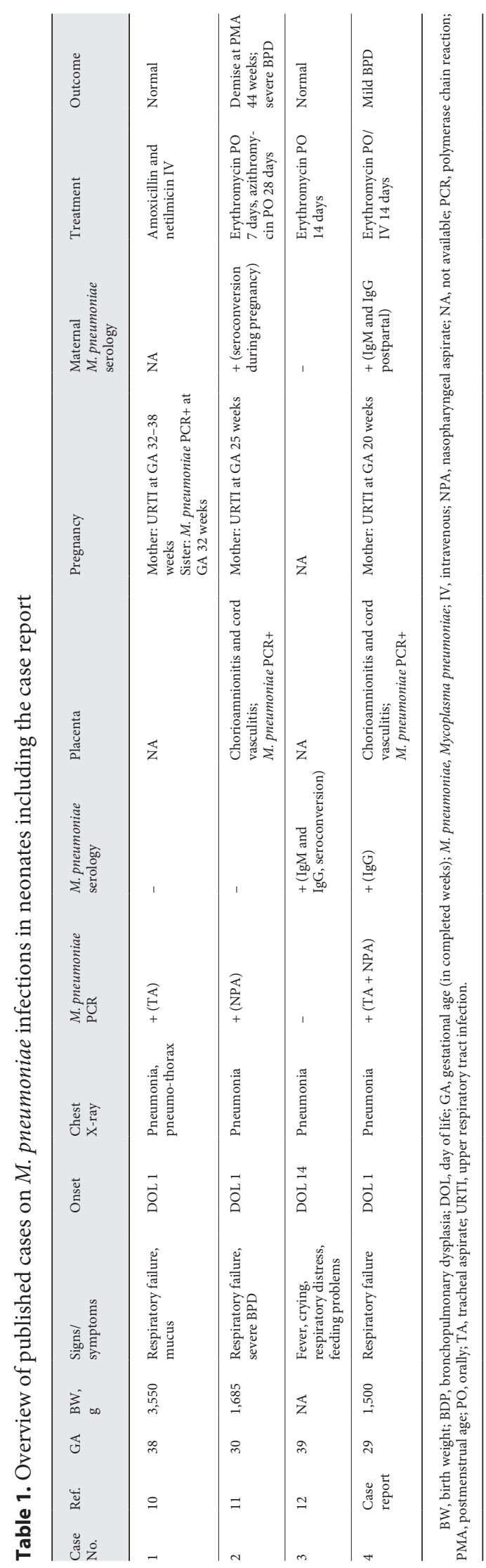

Congenital Mycoplasma pneumoniae Infection histochemistry; (3) detection of M. pneumoniae by PCR from neonatal respiratory specimens on DOL 3 and 4; and (4) neonatal pneumonia manifesting in the first hours of life and presenting as atypical RDS.

Invasive M. pneumoniae infection is rare [10], and vertical transmission of M. pneumoniae infection has been very rarely reported. To our knowledge, 3 cases of neonatal pneumonia associated with $M$. pneumoniae have been published so far (Table 1) [13-15]. Vertical transmission of $M$. pneumoniae infection has been suggested in 2 preterm neonates with either rapidly or slowly progressing respiratory failure requiring mechanical ventilation immediately after birth. A vertical route of transmission was confirmed in 1 case with the detection of $M$. pneumoniae DNA by PCR in placental tissue. We additionally showed by immunohistochemical analysis that $M$. pneumoniae is present in the placenta.

Interestingly, anti-M. pneumoniae IgG, but not IgM, was detected in the neonate on DOL 22. The detection of specific IgG is complicated by transplacental transfer of maternal antibodies. In contrast, the detection of IgM is very specific to the fetal compartment because IgM does not cross the placenta. However, the neonate's immune system may not mount an antibody response as effective as adults [16], and, most importantly, a negative IgM result does not exclude congenital infection $[17,18]$. Further, the antibody response to $M$. pneumoniae is complex [19]. We present only the second case of neonatal pneumonia associated with $M$. pneumoniae, in which the antibody response was assessed (Table 1). One might speculate that the presence or absence of M. pneumoniae-specific IgM may discriminate between perinatal infection after birth (case 3 , Table 1 ) and congenital infection (present case).

This case demonstrates that $M$. pneumoniae can be considered as possible cause of congenital pneumonia in addition to other "atypical" organisms. The route of transmission of $M$. pneumoniae is vertical infection after dissemination of the bacteria following maternal respiratory tract infection. Chorioamnionitis likely induced premature birth, but it remains unclear whether M. pneumoniae triggered also bronchopulmonary dysplasia as reported for ureaplasmas.

\section{Acknowledgments}

We thank the technicians of the Institute of Medical Microbiology, University of Zurich, for their assistance with microbiological analyses, and Silvia C. Estevão (Laboratory of Pediatrics, Erasmus MC - Sophia Children's Hospital, Rotterdam) for her assistance 
with immunohistochemical analyses. P.M.M.S. was supported by grants of the Promedica and Starr International Foundation, and a Fellowship Award of the European Society for Paediatric Infectious Diseases (ESPID), all outside the submitted work.

\section{Statement of Ethics}

Informed consent has been obtained.

\section{Disclosure Statement}

There is nothing to disclose.

\section{Funding Source}

There is no funding to disclose.

\section{Author Contributions}

B.M.H., P.H., G.N.: patient care and routine diagnostic workup; P.M.M.S., W.W.J.U., M.R.E., S.B., G.V.B., C.B.: microbiological, histological, immunohistochemical analyses; P.M.M.S., C.B.: writing the manuscript; C.B.: coordinating the work; all authors: critically reviewing the manuscript.

\section{References}

1 Spuesens EB, Fraaij PL, Visser EG, Hoogenboezem T, Hop WC, van Adrichem LN, Weber F, Moll HA, Broekman B, Berger MY, van Rijsoort-Vos T, van Belkum A, Schutten M, Pas SD, Osterhaus AD, Hartwig NG, Vink C, van Rossum AM: Carriage of Mycoplasma pneumoniae in the upper respiratory tract of symptomatic and asymptomatic children: an observational study. PLoS Med 2013;10: e1001444.

2 Jain S, Williams DJ, Arnold SR, Ampofo K, Bramley AM, Reed C, Stockmann C, Anderson EJ, Grijalva CG, Self WH, Zhu Y, Patel A, Hymas W, Chappell JD, Kaufman RA, Kan JH, Dansie D, Lenny N, Hillyard DR, Haynes LM, Levine M, Lindstrom S, Winchell JM, Katz JM, Erdman D, Schneider E, Hicks LA, Wunderink RG, Edwards KM, Pavia AT, McCullers JA, Finelli L; CDC EPIC Study Team: Community-acquired pneumonia requiring hospitalization among US children. N Engl J Med 2015;372:835-845.

3 Waites KB, Katz B, Schelonka RL: Mycoplasmas and ureaplasmas as neonatal pathogens. Clin Microbiol Rev 2005; 18:757-789.

4 Viscardi RM: Ureaplasma species: role in neonatal morbidities and outcomes. Arch Dis Child Fetal Neonatal Ed 2014;99:F87-F92.

5 Hardegger D, Nadal D, Bossart W, Altwegg M, Dutly F: Rapid detection of Mycoplasma pneumoniae in clinical samples by real-time PCR. J Microbiol Methods 2000;41:45-51.
6 Pascual A, Jaton K, Ninet B, Bille J, Greub G: New diagnostic real-time PCR for specific detection of Mycoplasma hominis DNA. Int J Microbiol 2010;2010:317512.

7 Xiao L, Glass JI, Paralanov V, Yooseph S, Cassell GH, Duffy LB, Waites KB: Detection and characterization of human Ureaplasma species and serovars by real-time PCR. J Clin Microbiol 2010;48:2715-2723.

8 Hooven TA, Polin RA: Pneumonia. Semin Fetal Neonatal Med 2017;22:206-213.

9 Neimark H, Gesner M: Is Mycoplasma pneumoniae adherence to erythrocytes a factor in extrapulmonary dissemination? PLoS Pathog 2010;6:e1001219.

10 Meyer Sauteur PM, Jacobs BC, Spuesens EB, Jacobs E, Nadal D, Vink C, van Rossum AM: Antibody responses to Mycoplasma pneumoniae: role in pathogenesis and diagnosis of encephalitis? PLoS Pathog 2014;10:e1003983.

11 Narita M: Pathogenesis of neurologic manifestations of Mycoplasma pneumoniae infection. Pediatr Neurol 2009;41:159-166.

12 Narita M: Pathogenesis of extrapulmonary manifestations of Mycoplasma pneumoniae infection with special reference to pneumonia. J Infect Chemother 2010;16:162-169.
13 Ursi D, Ursi JP, Ieven M, Docx M, Van Reempts P, Pattyn SR: Congenital pneumonia due to Mycoplasma pneumoniae. Arch Dis Child Fetal Neonatal Ed 1995;72:F118-F120.

14 Srinivasjois RM, Kohan R, Keil AD, Smith NM: Congenital Mycoplasma pneumoniae pneumonia in a neonate. Pediatr Infect Dis J 2008;27:474-475.

15 Kumar S, Maria A, Saigal SR, Maheshwari M Mycoplasma pneumoniae as a cause of nonresolving pneumonia in a neonate. J Med Microbiol 2010;59:731-732.

16 Hassan J, Dooley S, Hall W: Immunological response to cytomegalovirus in congenitally infected neonates. Clin Exp Immunol 2007; 147:465-471

17 Herremans T, Kortbeek L, Notermans DW: A review of diagnostic tests for congenital syphilis in newborns. Eur J Clin Microbiol Infect Dis 2010;29:495-501.

18 Coll O, Benoist G, Ville Y, Weisman LE, Botet F, Anceschi MM, Greenough A, Gibbs RS, Carbonell-Estrany X; WAPM Perinatal Infections Working Group: Guidelines on CMV congenital infection. J Perinat Med 2009;37: 433-445.

19 Meyer Sauteur PM, de Bruijn ACJM, Graça C, Tio-Gillen AP, Estevão SC, Hoogenboezem T, Hendriks RW, Berger C, Jacobs BC, van Rossum AMC, Huizinga R, Unger WWJ: Antibodies to protein but not glycolipid structures are important for host defense against Mycoplasma pneumoniae. Submitted. 